\title{
Knowledge and suberogatory assertion
}

\author{
John Turri
}

Published online: 2 March 2013

(C) Springer Science+Business Media Dordrecht 2013

\begin{abstract}
I accomplish two things in this paper. First I expose some important limitations of the contemporary literature on the norms of assertion and in the process illuminate a host of new directions and forms that an account of assertional norms might take. Second I leverage those insights to suggest a new account of the relationship between knowledge and assertion, which arguably outperforms the standard knowledge account.
\end{abstract}

Keywords Knowledge $\cdot$ Assertion $\cdot$ Norms $\cdot$ Suberogation $\cdot$ Rules

\section{Simple or not}

The current debate over the norms of assertion has been fundamentally shaped by Timothy Williamson's defense of the knowledge account of assertion. ${ }^{1}$ The case for the knowledge account has since been contested, defended, extended and refined. ${ }^{2}$ But one aspect of the debate, inherited from Williamson's initial discussion, has come in for surprisingly little scrutiny, namely, the narrow focus on competing "simple" accounts of the norm of assertion.

\footnotetext{
1 Williamson (1996, 2000 chap. 11).

2 E.g. DeRose (2002), Hawthorne (2004), Weiner (2005), Douven (2006), Lackey (2007), Hill and McKinnon and Turri (2013), and Turri (2010a, b, 2011a, b, 2012a, c, 2013a, e).

J. Turri $(\bowtie)$

Department of Philosophy, University of Waterloo, 200 University Avenue West, Waterloo, ON, Canada e-mail: john.turri@gmail.com
} Schechter (2007), Kvanvig (2009), Sosa 2009, Benton (2011), Benton (2013), Pelling (2011, 2012), 
What is a simple account? ${ }^{3}$ Simple accounts are singular because they say there is exactly one norm for assertion. The norm is rule-like because it stipulates that you have permission, or authority, to make an assertion only under certain conditions. The norm is perfect because it imposes a perfect duty, one that applies strictly to each and every assertion. The norm is concurrently restrictive because the condition must be satisfied prior to or at the time of assertion, rather than afterward. The norm is discretionary because it leaves it to your discretion whether you exercise your permission to assert; it doesn't obligate you to make any assertion. The norm is offensive because violating it justifies others in taking —or is at least apt to incite others to take-offense at your assertion, which might take the form of criticism or resentment. (Such an offense could be defeasible and excusable.) The norm is constitutive because it constitutes the speech act of assertion, just as the rules of a game constitute the game, in that they are essential to making the game the game that it is. Assertion, on this view, is a normatively constituted activity, such that a speech act is an assertion if and only if it is subject to the relevant norm. The norm is individuating because assertion is the unique speech act that has the rule as its unique constitutive rule. ${ }^{4}$

In short, a simple account says that there is a single, rule-like, perfect, restrictive, discretionary, offensive, constitutive, individuating norm of assertion, which has the form:

You may assert Q only if $\mathrm{Q}$ is $\mathrm{S}^{5}$

\section{Call this form the Simple Schema.}

Simple accounts differ over what they substitute for ' $S$ ' in the Simple Schema. If the account is to remain simple, in any recognizable sense of 'simple', then disjunctive and complex relational properties can't be substituted for ' $S$ '. Popular candidates for a simple rule have featured truth, belief, justification, certainty and knowledge.

- The Truth Rule: you may assert Q only if Q is true. (Weiner 2005)

- The Reasonableness Rule: you may assert Q only if it is reasonable for you to believe that Q. ${ }^{6}$ (Douven 2006; Lackey 2007)

\footnotetext{
3 I don't wish to debate the decision to use the label 'simple' for these accounts, even though, as will be evident to the reader soon enough, so-called simple accounts carry a surprising number of theoretical commitments. Using 'simple' to label views that share the ten features discussed below is largely a matter of deference to the way the literature has unfolded to this point, including most obviously Williamson's decision to classify his own account and some main competitors as 'simple'. If we wish, instead of 'simple' we could say 'purportedly simple' or 'orthodox' or some such. It makes no substantive difference.

${ }^{4}$ Standard accounts also typically state or presuppose that the norm is invariant because it demands the same thing of assertors in all contexts. A contextualist account of the norm would reject this (see DeRose 2002; but compare Turri 2010a and Turri 2013c). Here I set this dispute aside.

5 Williamson (2000, p. 241) says, 'one must: assert $p$ only if $p$ has C', but I prefer 'may' for permission and ' $\mathrm{S}$ ' as a mnemonic for 'simple'. Elsewhere Williamson uses 'if and only if' instead of 'only if' (e.g. 2000 , p. 265). We could distinguish, then, between weak and strong Simple Schemas: weak schemas state only a necessary condition, whereas strong schemas state necessary and sufficient conditions. I won't dwell on the distinction, since it isn't pertinent to my present goals. For simplicity, in the main text I restrict myself to weak schemas.

${ }^{6}$ More literally after the manner of the Simple Schema, but less naturally: you may assert Q only if Q is reasonable for you to believe. The rules that follow are likewise stated more naturally, although they could be brought strictly into Simple Schematic form.
} 
- The Belief Rule: you may assert Q only if you believe that Q. (Bach and Harnish 1979; Bach 2008)

- The Reasonable Belief Rule: you may assert Q only if you reasonably believe that Q. (Hill and Schechter 2007; Kvanvig 2009)

- The Certainty Rule: you may assert Q only if you are certain that Q. (Stanley 2008)

- The Knowledge Rule: you may assert Q only if you know that Q. (Unger 1975; Williamson 2000; DeRose 2002)

An account of the norm of assertion could deviate from a simple account in many ways. It could deviate by endorsing one or more of the following.

1. Nihilism: assertion has no norm

2. Imperfect: assertion's norm imposes an imperfect duty

3. Plurality: assertion has more than one norm

4. Nondeontological: assertion has a non-rule-like norm

5. Ex post facto: the norm pertains to what may happen after the assertion

6. Compulsory: the norm obligates you to make assertions under certain conditions

7. Inoffensive: violating the norm does not justify others in taking offense

8. Extrinsic: the norm does not help constitute assertion

9. Vulgar: the norm does not uniquely constitute assertion

10. Aschematic: the Simple Schema is incorrect

The main reason Williamson offers in favor of a simple account is that it would be 'theoretically satisfying, if it worked.' Williamson proceeds to defend a simple knowledge account, while 'shirking the examination of more complex accounts' (Williamson 2000, pp. 241-242).

\section{Two previous non-simple accounts}

This section discusses, in broad outline, two non-simple accounts of assertion. The purpose of this is to provide some context for introducing a different alternative to simple accounts, which allows us to re-imagine the relationship between knowledge and assertion in light of the most persistent objections to the simple knowledge account found in the literature.

Closely related to the simple account is a group of aschematic accounts that impose a further constraint on the manner of permissible assertion. For instance, it has been argued that the Knowledge Rule is lacking in at least one crucial respect. Suppose you know that Q and you assert that Q. However, suppose further that your assertion isn't based on your knowledge but is instead just a random statement of some proposition; or perhaps it's based solely on your desire to amuse your audience, along with your estimation that this would be an amusing assertion to make, offered without regard for its truth value. Such an assertion seems defective qua assertion because it fails to express your relevant knowledge, however well it serves your ulterior motives. Analogous examples suggest that the Belief Rule, Reasonable Belief Rule, and Certainty Rule are 
all likewise lacking. What seems missing from all these simple rules is a proper basing or expression requirement on permissible assertion (Turri 2011a). ${ }^{7}$

Such observations motivate a different class of accounts of assertion, what we might call express accounts. Express accounts feature express rules, such as:

- The Express Belief Rule: you may assert Q only if your assertion expresses your belief that $\mathrm{Q}$.

- The Express Reasonable Belief Rule: you may assert Q only if your assertion expresses your reasonable belief that Q.

- The Express Knowledge Rule: you may assert Q only if your assertion expresses your knowledge that Q.

- The Express Certainty Rule: you may assert Q only if your assertion expresses your certainty that $\mathrm{Q}$.

An express account differs from its simple cousin by imposing a further constraint on the manner or basis of permissible assertion. Recall that a simple account posits a single, rule-like, perfect, restrictive, constitutive, individuating norm of assertion, which has the form 'you may assert Q only if Q is S'. An express account posits a single, rule-like, restrictive, offensive, constitutive, individuating norm of assertion, which has the form 'you may assert Q only if Q is $\mathrm{S}$ and your assertion is $E$ '. But, of course, for appropriately chosen values for ' $E$ ' and ' $S$ ', the fact that your assertion is $\mathrm{E}$ entails that $\mathrm{Q}$ is $\mathrm{S}$. For example, suppose that $\mathrm{E}$ is 'expresses your knowledge that Q' and $\mathrm{S}$ is 'known by you'. Accordingly, we could define the Express Schema as follows:

You may assert Q only if your assertion is E.

A rule fitting the Express Schema would seem to have just as much a right to the title 'simple' as does a rule fitting the Simple Schema. But ultimately it matters little whether we apply the label 'simple' to express rules or not. Express rules and their simple cousins differ in one important respect, but they share several important commitments about the nature of the norm of assertion. For present purposes, the important thing is to understand where they agree and disagree.

Also differing from the simple account is a group of ex post facto accounts that say assertion's norm imposes dialectical obligations on the assertor downstream from assertion. Call these ex post facto dialectical accounts. On the most natural way of developing this view, the norm of assertion stipulates how you must respond if your assertion is challenged, rather than placing prior restraint on what you may assert initially (Rescorla 2009). An ex post facto dialectical account might endorse

- The Defend or Retract Rule: If you assert Q, then if your assertion is challenged, then you must either provide a good argument for $\mathrm{Q}$, or else retract your assertion. ${ }^{8}$

\footnotetext{
7 Turri (2011a) also hints at an openness to Extrinsic.

8 Such an account is thus not only ex post facto but also aschematic, because it deviates from the Simple Schema. But not all ex post facto accounts are aschematic. For instance consider the Immediate Retraction Account, which endorses the follow rule: you may assert P only if you then immediately
} 
One part of the motivation for the dialectical account is dissatisfaction with the evidence presented thus far for accepting that assertion's norm is concurrently restrictive. The other part of the motivation comes from the idea that assertion is essentially related to the speech acts of questioning and challenging, and thus is individuated by its role in 'the game of giving and asking for reasons' (Rescorla 2009, p. 102).

\section{The main argument for a knowledge account of assertion}

The primary and most widely recognized evidence for the simple knowledge account of assertion is an explanatory argument from linguistic patterns surrounding the give and take of assertion. Here are some data points:

(A) When you assert Q, even if Q has nothing to do with you or what you know, it's normally appropriate to ask you 'How do you know that?'

(B) It is understood as an implicit challenge to your assertion to ask you 'How do you know that?'. It is understood as explicitly challenging your assertion to ask you 'Do you really know that?'. And it is understood as explicitly rejecting your assertion to say 'You don't know that!'.

(C) If someone asserts Q, and it turns out that he doesn't know Q, then we judge the assertion negatively. ${ }^{9}$ And if he asserts $Q$ but knows that he doesn't know Q, then we judge him negatively.

(D) When you're asked whether Q, even when $\mathrm{Q}$ has nothing to do with you or what you know, normally it's okay to respond by saying 'I don't know'.

(E) In response to a question, the statements 'I don't know', 'I can't tell' and 'I can't say' are practically interchangeable.

(F) Assertions of the form ' $Q$ but I don't know that Q' strike us as infelicitous.

(G) Assertions of the form 'I don't know whether Q, but I can tell you that Q' strike us as infelicitous.

The simple knowledge account's proponents point out that their view provides a unified explanation of this entire range of data, whereas none of its simple competitors can explain it all, much less equally well explain it all (Williamson 2000, chap. 11; Turri 2011a).

\section{The main objection to the simple knowledge account}

The main objection to the simple knowledge account is that it forbids intuitively permissible assertions.

Footnote 8 continued

retract P. (Of course this account is implausible, but that's beside the point.) Similarly not all dialectical accounts are purely ex post facto accounts. For instance, on Rescorla's (2009, p. 100) reading, Brandom (1994) advocates a mixed account, which also accepts a concurrent restriction on assertion, to the effect that you may assert P only if you have sufficient warrant to believe P. On this interpretation, Brandom accepts Ex Post Facto and Plurality.

9 Sometimes it is said that we are entitled to 'resent' such an assertion (Williamson 2000, p. 246; Turri 2011a; compare Weiner 2005). But 'resent' seems too strong in many cases where it turns out that the speaker doesn't know, as in some of the cases discussed in Sect. 4 below. 
Critics advance two main types of example to substantiate this objection. First, there are examples where a subject asserts something that he reasonably but falsely believes. Given the uncontroversial assumption that knowledge is factive (i.e. necessarily, if you know Q, then $\mathrm{Q}$ is true),${ }^{10}$ if such assertions are permissible, then the simple knowledge account is false. Second, there are Gettiered assertions, where a subject has a justified true belief that Q, and asserts Q, but is in a Gettier situation and so doesn't know Q. Given the widespread assumption that Gettier subjects don't have knowledge, ${ }^{11}$ if Gettiered assertions are permissible, then the simple knowledge account is false. ${ }^{12}$

The standard response to this objection is to draw a distinction between the impermissible and the blameworthy (see Williamson 2000; compare DeRose 2002). These ignorant assertions, as we might call them, are not blameworthy because the assertors were justified in believing that they were making a permissible assertion. We excuse people and do not blame them when they do something wrong, if they were justified in thinking it was not wrong. Nevertheless, the excuse doesn't make their action right. An ignorant assertion might be excusable, but it's not permissible.

While the response is certainly ingenious, not all critics have been persuaded. One way to understand their dissatisfaction is to consider what they've said about the relation between permissibility and the propriety of apologizing (Kvanvig 2009, pp. 145-149). Apologizing is called for if you have done something impermissible. In the case of a false but reasonable assertion, and especially in the case of a Gettiered assertion, an apology for the assertion seems not to be called for. While it is perhaps understandable that a person in such a situation would retract their assertion upon being apprised of the unfortunate and unlikely details of their situation, it would strike us as overblown if they proceeded to apologize for making the assertion. The fact that an apology is not called for, the critic claims, strongly suggests that nothing impermissible has occurred.

So where does this leave the simple knowledge account of assertion? It clearly has impressive explanatory power, but some are troubled by its purportedly counterintuitive implications in some cases, and they charge that this outweighs its explanatory virtues. It's at this point that I would like to take a step back and explore other options, and in particular whether we have overlooked ways of relating knowledge to assertion that have the same explanatory power as the simple knowledge account but which don't encounter such resistance in special cases of ignorant assertion.

\footnotetext{
$\overline{10}$ But see Hazlett (2010), Turri (2011c, 2013d), and Buckwalter (2013) for more on this assumption.

11 For dissent see Hetherington (1998, 1999), Weatherson (2003), Turri (2012b) and Starmans and Friedman (2012); but see also Turri (2011d) and Turri (2013b).

12 A third, more controversial type of example involves non-Gettiered justified true beliefs, which supposedly nevertheless fall short of knowledge because the subject's justification isn't strong enough to yield knowledge. This class of cases includes lottery propositions, as well as predictions and retrodictions based on evidence recognized to be incomplete or otherwise insufficient for knowledge. See Weiner and 2005. Williamson (2000, p. $246 \mathrm{ff}$.) takes the standard reaction to assertions in lottery cases to favor his simple knowledge account. I view lottery cases more ambivalently; see Turri (2011e) and Turri and Friedman (2013).
} 


\section{Suberogation}

You enter some shabby government office to take care of some annoying paperwork for some irritating responsibility. The room is packed. A sign yellowing with age greets you as you enter, 'Please take a number and we will be happy to assist you shortly.' You take a number, 117, note with disgust that they're presently serving number 9, sit down in one of the cheap, small plastic chairs crammed along the wall, and patiently wait your turn. Hours slowly pass. Finally, your turn approaches. 'Now serving number 114,' the electronic display reads. You welcome the thought of soon being done with this unpleasant and aggravating experience. But you're also somewhat concerned about the older woman sitting across from you. As difficult as this long wait in cramped, uncomfortable quarters has been for you, it's clearly been more difficult for her. It is essential that she stay and resolve an urgent matter regarding her pension, she tells you, but her aching hip isn't making it easy. She continues in earnest, 'I see that you have number 117. I have number 122. Would you mind trading numbers with me, please? I could manage either way, of course, but extending me this favor would be a relief.' Granting her request would require you to wait in line about an extra 10 minutes.

It would be good for you to do her this favor. We would praise you for switching numbers; we would think less well of you if you didn't switch numbers; we might even offer some gentle criticism after the fact; and arguably if you don't switch numbers, then you should later regret your decision. All this despite our recognizing that you have a right to your number, that you'd be within your rights to refuse her request, and thus that your refusing to switch is morally permissible. In a word, refusing to do the favor in this case is bad but permissible. ${ }^{13}$

A bad but permissible action is suberogatory (Driver 1992; Chisholm 1963 calls it an 'offence'). This is the inverse of the supererogatory. A supererogatory act is good but not required. The supererogatory is an important normative category that helps us understand our moral judgments about actions in the interval spanning the required and the heroic. Similarly the suberogatory helps us, as Julia Driver puts it, to shed light on our normative judgments 'lying in the dark corners between right and wrong' (1992, p. 295).

\section{A new role for knowledge}

I will now consider a non-simple knowledge account that builds on the insights from the previous section. This alternative posits a nondeontological, aschematic knowledge norm and accepts that there is a plurality of assertional norms (thus deviating from the simple knowledge account by accepting points 3,4 and 10 at the end of Sect. 1 above).

We have already seen that there are permissible but bad actions. I hypothesize that reasonable ignorant assertions are suberogatory assertions. This follows if we

\footnotetext{
13 For those who don't share the intuition about the case as described: adjust the case by increasing the older woman's ticket number just enough until you feel it would no longer be wrong for you to refuse.
} 
accept four things. First, by analogy with the ethical case, suberogatory assertions are permissible but bad assertions. Second, reasonable belief sets the standard for permissible assertion (that is, you may assert Q only if you reasonably believe Q). ${ }^{14}$ Third, reasonable belief doesn't suffice for knowledge. Fourth, your assertion is good only if you know what you assert (or: you well assert that Q only if you know that Q). ${ }^{15}$ For convenience, by 'good' here we mean 'not bad', so this is equivalent to saying that your assertion is bad unless you know what you assert. If we want a label for this type of view, let's call it a pluralist axiological knowledge account of assertion, or a $P K$ account for short.

Two points of clarification before proceeding. First, I don't claim to explain why your assertion is good only if you know what you assert. Rather, I'm hypothesizing this as part of a theory about assertional norms that well explains important facts about the practice of assertion. Second, the example of ethical suberogation might imply that I'm proposing that non-knowledgeable assertions are ethically suberogatory. I hereby cancel any such implication. I don't claim that non-knowledgeable assertions are necessarily ethically bad. (Of course, that they are necessarily ethically bad is a possible view, but one I do not hold.) Rather, the current proposal is that the badness is internal to the practice of assertion-bad qua assertion. ${ }^{16}$ To help illustrate the idea, consider that in many games there are moves that are permitted but bad in the game. For example, in tennis it's bad to hit the ball into the net, and in basketball it's bad to foul an opponent. Nevertheless, hitting the ball into the net is permitted in tennis, and fouling an opponent is permitted in basketball. ${ }^{17}$

How well does the PK account compare to the simple knowledge account? To answer this question, let's see how well it fares in the featured cases of reasonable ignorant assertion, and how well it explains the linguistic data that a simple knowledge account is put forward to explain.

The special cases of reasonable ignorant assertion were put forward as counterexamples to the simple knowledge account. They are touted as counterexamples because, critics claim, they are intuitively permissible assertions. The simple

\footnotetext{
14 If one is impressed by Lackey's cases of "selfless assertion," then it is harmless to substitute here 'you may assert Q only if it is reasonable for you to believe Q'. (For reasons to not be impressed by cases of selfless assertion, see Turri 2013a; relatedly, see Buckwalter et al. 2013, and Buckwalter and Turri 2013.) Also, I should note that the motivation for this second claim is two-fold. On the one hand, it is the most popular competitor to the simple knowledge account in the literature, and I am interested here in accommodating the intuitions of those who favor such a view. On the other hand, it is required in order for reasonable ignorant assertions to be suberogatory, on the standard definition of that normative category (as reflected in the first of the four claims from which my hypothesis follows). (Thanks to an anonymous referee for pointing out the need for further explanation here.)

15 The analogous express rule would be 'you well assert that $\mathrm{Q}$ only if your assertion expresses your knowledge that Q'. I favor the express formulation but won't pursue the matter further here.

16 For one account of the sort of normativity or value at stake here, see Turri (2013f).

17 I thank an anonymous referee for suggesting that I clarify that I'm not proposing that nonknowledgeable assertions are ethically bad, and for suggesting the analogy with permitted but bad moves in games.
} 
knowledge account entails that they are impermissible. But the PK account entails that they are permissible. So the PK account completely avoids this problem. ${ }^{18}$

Can a PK account explain the linguistic data that the simple account explains? It does so surprisingly well.

(A) When you assert Q, it is normally appropriate to ask you 'How do you know that?' because we're asking you whether you performed well, and thus whether what you've done was worth doing. As the common saying goes, anything worth doing is worth doing well.

(B) We can apply similar reasoning to the range of aggressiveness felt from 'How do you know that?' to 'Do you really know that?' to 'You don't know that!' In the first case we' re implicitly suggesting that you're not performing well, in the second we're explicitly suggesting that you're not performing well, and in the third we're explicitly accusing you of not performing well.

(C) When you're asked whether Q, normally it's okay to respond by saying 'I don't know'. This is because you're informing your interlocutor that you're not positioned to answer well, and so your answer isn't worth giving.

(D) If someone asserts Q, and it turns out that he doesn't know Q, then we judge the assertion negatively. This is because the assertion is bad, which of course merits a negative judgment (qua assertion). And if he asserts $\mathrm{Q}$ while knowing that he doesn't know $Q$, then we judge him negatively, because he knowingly performs poorly.

(E) Assertions of the form 'Q but I don't know that Q' strike us as infelicitous. If the PA account is correct, then this is like saying ' $Q$ but asserting $Q$ is a bad thing for me to do' or ' $Q$ but I'm poorly positioned to be making such a claim'. These are odd because they are akratic assertions. We generally find akratic behavior puzzling.

(F) Assertions of the form 'I don't know whether Q, but I can tell you that Q' also strike us as infelicitous. This is because they are tantamount to the akratic assertions noted in (E). Uttering 'I can tell you that Q' or 'what I can tell you is, Q' is a way of indirectly asserting Q.

(G) In response to a question, the replies 'I don't know', 'I can't tell' and 'I can't say' are practically interchangeable. We suppose that 'can' here is elliptical for 'can do so well'. So 'I don't know' communicates practically the same thing as 'I can't well tell you' or 'I can't very well say'. And it is acceptable to decline a request when you can't well fulfill it.

Returning to our question, 'how well does the PK account compare to the simple knowledge account?', and supposing for the sake of argument that the special cases of ignorant assertion are at least plausible candidates for permissible assertion, the

\footnotetext{
${ }^{18}$ To the extent there is a problem, that is. I'm willing to grant for the sake of argument that there is a problem here. For those to whom it seems that these ignorant assertions are impermissible, such cases will seem like counterexamples to the PA knowledge account, and there will be little if any motivation to abandon the simple account. It's often assumed that the intuition is widely shared that reasonable ignorant assertions are permissible. But empirical investigation casts serious doubt on that assumption; see Turri (2013e).
} 
PK account seems to outperform its cousin. In the first place, the PK account entails that reasonable ignorant assertions are permissible, whereas the simple account entails the opposite. In the second place, the PK offers to explain all of the linguistic data points that the simple account explains.

In short, for those impressed by the simple account's explanatory power but troubled by what it entails in special cases of ignorant assertion, the PA account is preferable: it offers enhanced extensional adequacy combined with comparable explanatory fruitfulness.

\section{Conclusion}

I accomplished two main things in the paper. First, I identified ten assumptions that have structured contemporary theorizing about assertional norms. Explicitly identifying these assumptions enables us to readily organize a burgeoning literature and also imagine a host of hitherto unarticulated views about the nature of assertional norms, which future work in the area can profitably explore. Second, I proposed a new theory that vindicates the intuitive links between knowledge and assertion, while avoiding the primary objection to the standard knowledge account of assertion.

Acknowledgments For helpful feedback and conversation, I thank an anonymous referee for Philosophical Studies, Matt Benton, Mathieu Doucet, Tim Kenyon, Patricia Marino, Rachel McKinnon, Ernest Sosa, and Angelo Turri. Thanks also to audiences at Ryerson University, the 2012 Congress of the Canadian Philosophical Association, and the 2012 Orange Beach Epistemology Workshop. This research was kindly supported by the Social Sciences and Humanities Research Council of Canada, the British Academy, the Association of Commonwealth Universities, the National Endowment for the Humanities, The Character Project at Wake Forest University and the John Templeton Foundation (neither of which necessarily endorses any opinion expressed here), and an Ontario Early Researcher Award.

\section{References}

Bach, K. (2008). Applying pragmatics to epistemology. Philosophical Issues, 18, 68-88.

Bach, K., \& Harnish, R. M. (1979). Linguistic communication and speech acts. Cambridge, MA: MIT Press.

Benton, M. (2011). Two more for the knowledge account of assertion. Analysis. doi:10.1093/analys/ anr085.

Benton, M. (2013). Dubious objections from iterated conjunctions. Philosophical Studies, 162(2), $355-358$.

Brandom, R. (1994). Making it explicit. Cambridge, MA: Harvard University Press.

Buckwalter, W. (2013). Factive verbs and protagonist projection (under review).

Buckwalter, W, \& Turri, J. (2013). In the thick of moral motivation (under review).

Buckwalter, W., David, R., \& Turri, J. (2013). Belief through thick and thin (under review).

Chisholm, R. (1963). Supererogation and offence: A conceptual scheme for ethics. Ratio, 5(1), 1-14.

DeRose, K. (2002). Assertion, knowledge, and context. Philosophical Review, 111(2), 167-203.

Douven, I. (2006). Assertion, knowledge, and rational credibility. Philosophical Review, 115(4), $449-485$.

Driver, J. (1992). The suberogatory. Australasian Journal of Philosophy, 70(3), 286-295.

Hawthorne, J. (2004). Knowledge and lotteries. Oxford: Oxford University Press.

Hazlett, A. (2010). The myth of factive verbs. Philosophy and Phenomenological Research, 80(3), 497-522. 
Hetherington, S. (1998). Actually knowing. The Philosophical Quarterly, 48(193), 453-469.

Hetherington, S. (1999). Knowing failably. The Journal of Philosophy, 96(11), 565-587.

Hill, C. S., \& Schechter, J. (2007). Hawthorne's lottery puzzle and the nature of belief. Philosophical Issues, 17, 102-122.

Kvanvig, J. L. (2009). Assertion, knowledge, and lotteries. In D. Pritchard \& P. Greenough (Eds.), Williamson on knowledge (pp. 140-160). Oxford: Oxford University Press.

Lackey, J. (2007). Norms of assertion. Nô̂s, 41(4), 594-626.

McKinnon, R., \& Turri, J. (2013). Irksome assertions. Philosophical Studies (Forthcoming).

Pelling, C. (2011). A self-referential paradox for the truth account of assertion. Analysis. doi:10.1093/ analys/anr093.

Pelling, C. (2012). Paradox and the knowledge account of assertion. Erkenntnis. doi:10.1007/s10670012-9360-0.

Rescorla, M. (2009). Assertion and its constitutive norms. Philosophy and Phenomenological Research, $79(1), 98-130$.

Sosa, D. (2009). Dubious assertions. Philosophical Studies, 146(2), 269-272.

Stanley, J. (2008). Knowledge and certainty. Philosophical Issues, 18, 33-55.

Starmans, C., \& Friedman, O. (2012). The folk conception of knowledge. Cognition, 124(3), $272-283$.

Turri, J. (2010a). Epistemic invariantism and speech act contextualism. Philosophical Review, 119(1), 77-95.

Turri, J. (2010b). Prompting challenges. Analysis, 70(3), 456-462.

Turri, J. (2011a). The express knowledge account of assertion. Australasian Journal of Philosophy, 89(1), $37-45$.

Turri, J. (2011b). Promises to keep: Speech acts and the value of reflective knowledge. Logos \& Episteme, 2(3), 583-590.

Turri, J. (2011c). Mythology of the factive. Logos \& Episteme, 2(1), 143-152.

Turri, J. (2011d). Manifest failure: The gettier problem solved. Philosophers' Imprint, 11(8), 1-11.

Turri, J. (2011e). Contingent a priori knowledge. Philosophy and Phenomenological Research, 83(2), 327-344.

Turri, J. (2012a). Pyrrhonian skepticism meets speech-act theory. International Journal for the Study of Skepticism, 2, 83-98.

Turri, J. (2012b). Is knowledge justified true belief? Synthese, 184(3), 247-259.

Turri, J. (2012c). Preempting paradox. Logos \& Episteme, 3(4), 659-662.

Turri, J. (2013a). You gotta believe. In C. Littlejohn \& J. Turri (Eds.), Epistemic norms. Oxford: Oxford University Press (forthcoming).

Turri, J. (2013b). A conspicuous art: Putting gettier to the test. Philosophers' Imprint (forthcoming).

Turri, J. (2013c). Linguistic intuitions in context: A defense of nonskeptical pure invariantism." In A. Booth \& D. Rowbottom (Eds.), Intuitions. Oxford: Oxford University Press (forthcoming).

Turri, J. (2013d). Knowledge as achievement, more or less. In M. F. Vargas (Ed.), The present and future of virtue epistemology (forthcoming).

Turri, J. (2013e). The test of truth: an experimental investigation of the norm of assertion (under review).

Turri, J. (2013f). Sustaining rules: A model and application (under review).

Turri, J, \& Friedman, O. (2013) Winners and losers in the folk epistemology of lotteries. In J. Beebe (Ed.), Advances in experimental epistemology. London: Continuum (forthcoming).

Unger, P. (1975). Ignorance: A case for skepticism. Oxford: Oxford University Press.

Weatherson, B. (2003). What good are counterexamples? Philosophical Studies, 11(1), 1-31.

Weiner, M. (2005). Must we know what we say? Philosophical Review, 114(2), 227-251.

Williamson, T. (1996). Knowing and asserting. Philosophical Review, 105(4), 489-523.

Williamson, T. (2000). Knowledge and its limits. Oxford: Oxford University Press. 